\title{
Article
}

\section{Dietary zinc intake and whole blood zinc concentration in subjects with type 2 diabetes versus healthy subjects: A systematic review, meta-analysis and meta-regression}

Fernández-Cao, José C., Warthon-medina, Marisol, Moran, Victoria Louise, Arija, Victoria, Doepking, Carlos and Lowe, Nicola M

Available at http://clok.uclan.ac.uk/21601/

Fernández-Cao, José C., Warthon-medina, Marisol, Moran, Victoria Louise ORCID: 0000-0003-3165-4448, Arija, Victoria, Doepking, Carlos and Lowe, Nicola M ORCID: 0000-0002-6934-2768 (2018) Dietary zinc intake and whole blood zinc concentration in subjects with type 2 diabetes versus healthy subjects: A systematic review, meta-analysis and meta-regression. Journal of Trace Elements in Medicine and Biology, 49 . pp. 241-251. ISSN 0946672X

It is advisable to refer to the publisher's version if you intend to cite from the work. http://dx.doi.org/10.1016/j.jtemb.2018.02.008

For more information about UCLan's research in this area go to http://www.uclan.ac.uk/researchgroups/ and search for <name of research Group>.

For information about Research generally at UCLan please go to http://www.uclan.ac.uk/research/

All outputs in CLoK are protected by Intellectual Property Rights law, including Copyright law. Copyright, IPR and Moral Rights for the works on this site are retained by the individual authors and/or other copyright owners. Terms and conditions for use of this material are defined in the policies page. 
Dietary zinc intake and whole blood zinc concentration in subjects with type 2 diabetes versus healthy subjects: A systematic review, meta-analysis and meta-regression

José C. Fernández-Caoa, b, *

aDepartamento de Nutrición y Dietética, Facultad de Ciencias de la Salud, Universidad de Atacama, Copiapó, Chile; bUnidad de Nutrición y Salud Pública, Facultad de Medicina y Ciencias de la Salud, Universitat Rovira i Virgili, Reus, Spain;

Postal address: Departamento de Nutrición y Dietética, Facultad de Ciencias de la Salud (Campus Cordillera), Universidad de Atacama, Avda. Copayapu 2862, 1570000 Copiapó, III Región, Chile

\section{E-mail: jose.fernandez.cao@uda.cl}

Marisol Warthon-Medina ${ }^{c, d}$

'Nutritional Epidemiology Group, School of Food Science and Nutrition, University of Leeds, Leeds, UK; International Institute of Nutritional Sciences and Applied Food Safety Studies, School of Sport and Wellbeing, University of Central Lancashire, Preston, UK.

Postal address: Nutritional Epidemiology Group, School of Food Science and Nutrition, University of Leeds, Woodhouse Ln, Leeds, LS2 9JT, UK.

E-mail: M.WarthonMedina@leeds.ac.uk

Victoria Hall Morane

eMaternal and Infant Nutrition and Nurture Unit, University of Central Lancashire, Preston, UK;

Postal address: Maternal and Infant Nutrition and Nurture Unit, University of Central Lancashire, Preston, PR 1 2HE, UK.

E-mail: VLMoran@uclan.ac.uk

Victoria Arijab

bUnidad de Nutrición y Salud Pública, Facultad de Medicina y Ciencias de la Salud, Universitat Rovira i Virgili, Reus, Spain;

Postal address: Unidad de Nutrición y Salud Pública, Facultad de Medicina y Ciencias de la Salud, Universitat Rovira i Virgili, C/ Sant Llorenç 21, 43201 Reus, Spain

E-mail: victoria.arija@urv.cat 
Carlos Doepkinga

aDepartamento de Nutrición y Dietética, Facultad de Ciencias de la Salud, Universidad de Atacama, Copiapó, Chile;

Postal address: Departamento de Nutrición y Dietética, Facultad de Ciencias de la Salud (Campus Cordillera), Universidad de Atacama, Avda. Copayapu 2862, 1570000 Copiapó, III Región, Chile

E-mail: carlos.doepking@uda.cl

Nicola M. Lowe

International Institute of Nutritional Sciences and Applied Food Safety Studies, School of Sport and Wellbeing, University of Central Lancashire, Preston, UK.

Postal address: International Institute of Nutritional Sciences and Food Safety Studies, Darwin Building, c/o Psychology School Office, University of Central Lancashire, Preston, Lancashire PR1 2HE, United Kingdom.

E-mail: NMLowe@uclan.ac.uk.

* Corresponding author: José C. Fernández-Cao, Departamento de Nutrición y Dietética, Facultad de Ciencias de la Salud (Campus Cordillera), Universidad de Atacama, Avda. Copayapu 2862, 1570000 Copiapó, III Región, Chile

E-mail: jose.fernandez.cao@uda.cl

Phone: +56522228054 118 .

Short title: Zinc and type 2 diabetes mellitus: systematic review and meta-analysis Keywords: Zinc; type 2 diabetes mellitus; review; EURRECA.

Abbreviations: T2DM, type 2 diabetes mellitus; EURRECA, EURopean micronutrient RECommendations Aligned; MD, mean difference; AAS, absorption spectrophotometry; ICPMS, inductively coupled plasma mass spectrometry; ICP-AES, inductively coupled plasma atomic emission spectrometry.

\section{Abstract}

The aim of this systematic review, meta-analysis and meta-regression was to examine the relationship between type 2 diabetes mellitus (T2DM) and concentration of zinc in whole blood, as well as dietary zinc intake. Searches were performed using Ovid MEDLINE, 
Embase (Ovid) and The Cochrane Library (CENTRAL). Observational studies conducted on diabetic and healthy adults, with data on dietary zinc intake and/or concentration of zinc in whole blood, were selected. The search strategy yielded 11,150 publications and the manual search 6 , of which 11 were included in the meta-analyses. Mean difference (MD) and 95\% confidence interval $(\mathrm{Cl})$, were calculated using the generic inverse-variance method with random-effects models. Heterogeneity was assessed by the Cochran Q-statistic and quantified by the $\mathrm{I}^{2}$ statistic. Meta-regressions and stratified analysis were used to examine whether any covariate had influence on the results. The pooled MD for the dietary zinc intake meta-analysis was $-0.40\left(95 \% \mathrm{Cl}:-1.59\right.$ to $\left.0.79 ; \mathrm{I}^{2}=61.0 \%\right)$. Differences between diabetic and non-diabetic subjects became significant in the presence of complications associated with diabetes (MD $=-2.26 ; 95 \% \mathrm{Cl}$ : -3.49 to $\left.-1.02 ; \mathrm{I}^{2}=11.9 \%\right)$. Meta-regression showed that for each year since the diagnosis of diabetes the concentration of zinc in whole blood decreased in diabetic patients regarding healthy controls [MD (concentration of zinc in blood $)=732.61+(-77.88303) \times$ (duration of diabetes in years) , which is not generally explained by a lower intake of zinc.

\section{Highlights}

Duration of T2DM is associated with a reduction in whole blood zinc concentration.

Dietary zinc intake seems not to explain differences in whole blood zinc concentration.

Only diabetics with complications seem to consume less zinc than healthy subjects.

\section{Introduction}

Zinc is an essential trace element that is directly implicated in the physiology of glucose metabolism, participating in the synthesis, storage, secretion, action and translocation of insulin into the cells [1-3], as well as translocation of GLUT4 to the cell surface for glucose transport into the insulin responsive cells [4]. Disturbances in zinc homeostasis may play a role in the pathogenesis [5,6], pathophysiology [7-9] and control [10-12] of type 2 diabetes mellitus (T2DM). In addition, it has been observed that T2DM patients with a good glycemic control had a higher zinc status compared to those with poor glycemic control [13]. T2DM is a major global health problem. The prevalence of diabetes worldwide was estimated as 415 million people aged 20-79 years in 2015, and it has been forecast to increase to 642 million in 2040 [14].

Several studies $[15,16]$, but not all $[17,18]$, have found a significantly lower concentration of zinc in whole blood in patients with T2DM compared with healthy subjects. Although blood zinc is not a sensitive biomarker of zinc status, red blood cells are rich in zinc, and changes in the concentration of zinc in whole blood may reflect alterations in red blood cell zinc transport. It has been proposed that a lower dietary zinc intake in diabetic individuals may 
explain the reduced plasma and whole blood zinc concentrations observed in some studies $[19,20]$. This seems to be supported by a dose-response relationship between zinc intake and zinc status in adult populations observed in a systematic review and meta-analysis [21]. However, differences in dietary zinc intake between patients with T2DM and healthy controls have not been confirmed by subsequent studies [22,23].

The purpose of this study was to undertake a systematic review, meta-analysis and metaregression of the published literature to examine the relationship between T2DM, concentration of zinc in whole blood, and dietary zinc intake.

\section{Material and methods}

This systematic review and meta-analysis was conducted within the framework of the EURopean micronutrient RECommendations Aligned (EURRECA) Network of Excellence. It has been recorded in PROSPERO (2015: CRD42015020178) and can be consulted here: (http://www.crd.york.ac.uk/PROSPERO/display_record.php?ID=CRD42015020178). The implementation of this systematic review and meta-analysis was performed following the MOOSE criteria statement [24].

Literature search

The search strategy was performed as part of a wider review process to identify studies assessing the effect of zinc on different outcomes. The searches were performed of literature published up to and including March 2016 in Ovid MEDLINE, Embase (Ovid) and The Cochrane Library (CENTRAL) using search terms for ('study designs in humans') AND (Zinc) AND (intake OR status). Manual searches of references supplemented the electronic search.

Study selection

To be included in the research, studies had to be original publications of observational design (prospective cohort, case-control, and cross-sectional), conducted on human adults ( $\geq 18$ years) with type 2 diabetes mellitus (T2DM) patients and healthy individuals as controls. In addition, included studies needed to report data on the mean and standard deviation of dietary zinc intake and/or concentration of zinc in whole blood in both diabetic and non-diabetic subjects. Animal and in vitro studies, studies with diabetic participants other than T2DM, and study designs other than prospective cohort, case-control, and crosssectional studies, were excluded.

The selection process was carried out in two stages, the first involved filtering studies by their title and abstract (Figure 1). In the second stage, potentially relevant studies were 
explored further using the full text of the article and assessed against the inclusion and exclusion criteria. Stages 1 and 2 were carried out by members of the team (JCFC, MWM, VHM, CD and NL). A $10 \%$ sample was cross checked by a second researcher to ensure consistency between reviewers and any discrepancies were resolved by discussion.

From each article selected for inclusion at stage 2, the following data were extracted into an excel spreadsheet: author, publication year, study design, sample size, control matched, geographical area, gender, age, BMI (Body Mass Index), complications associated with diabetes, duration of T2DM, dietary survey method used to estimate zinc intake, number of days of administration of the dietary survey, dietary zinc intake of participants, laboratory technique used to determine concentration of zinc in whole blood, and its concentrations (Table 1). The extracted data were checked independently by at least two researchers. In order to incorporate relevant data from those selected studies that presented results in forms other than the mean and standard deviation, such as median and the interquartile range, we used the estimation methods proposed by Wan et al. [25]. These methods allowed appropriate estimates to be made for both normal data and skewed data. Variables expressed as a range, such as age in diabetic and non-diabetic groups, duration of diabetes in diabetic subjects, were assigned the midpoint of the range to estimate a mean value. The quality of publications (Table S1) was evaluated using the STROBE Statement [26], and the score was used in the statistics analyses. If any of the data was missing, the authors were contacted for additional data.

Statistical analysis

Data were expressed as mean difference (MD) with 95\% confidence interval $(\mathrm{Cl})$, and pooled using the generic inverse-variance method with random-effects models. MD in both meta-analyses was calculated as the difference between the values of diabetics and those of non-diabetics. Forest plots were created to visualise summary estimates. Heterogeneity was assessed by the Cochran Q-statistic and quantified by the $\mathrm{I}^{2}$ statistic, which represents the percentage of variation attributable to between-study heterogeneity [27]. $\left.\right|^{2}$ values of $25 \%$, $50 \%$, and $75 \%$ were considered as low, medium, and high heterogeneity, respectively $[28,29]$. Potential sources of heterogeneity in both meta-analyses were explored by univariate meta-regressions (tables 2 and 3), using covariates such as geographic area, eastern (1) vs. western (2); continent, America (1), Asia (2), Oceania (3), and Europe (4); gender, men (1) vs. women (2); quality (STROBE Statement [26]), both categorical and continuous variables; age of diabetics patients and healthy controls, both categorical and continuous variables; BMI category in diabetic and non diabetic subjects, normal weight $\left(18.5-24.9 \mathrm{~kg} / \mathrm{m}^{2}\right)(1) \mathrm{vs}$. overweight $\left(25.0-29.9 \mathrm{~kg} / \mathrm{m}^{2}\right)(2)$, duration of diabetes, both 
categorical and continuous variables, complications associated with diabetes, without (1) vs. with complications (2); sample size, both categorical and continuous variables; matched, yes (1) vs. no (2); dietary survey method, 24-hour dietary recall (1) vs. dietary record (2); number of days of administration of the dietary survey, 1, 2, 3, 4 and 7 days and laboratory technique zinc assessment method to determine the concentration of zinc in whole blood, atomic absorption spectrophotometry (AAS) (1), inductively coupled plasma mass spectrometry or atomic emission spectrometry (ICP-MS or ICP-AES) (2).

Multivariate meta-regressions were used to examine the covariates that had a significant influence on heterogeneity in univariate analysis. Covariates showing collinearity were removed from the final multivariate model. In addition, to examine how much of the heterogeneity was accounted for by the studied covariates, the adjusted $\mathrm{R}^{2}$ was calculated by comparing the baseline value of the heterogeneity variance obtained from the empty regression model, with the heterogeneity variance from the meta-regression after the covariate was added. Finally, stratified analysis was also used in order to assess possible causes of heterogeneity.

Random effects meta-regressions were also used to examine whether any covariate had influence on the results. Bubble plots were created to show a relevant influence of a single continuous covariate on MDs in a meta-regression model. This graph represents the fitted regression line together with circles representing the estimates from each study, sized according to the precision of each estimate (the inverse of its within-study variance). Publication bias was investigated by visual inspection of funnel plots and quantitatively assessed using Egger's [30] and Begg's [31] tests.

To test the influence of each study on the overall effect size, sensitivity analysis was conducted using Leave-One-Out method, that is removing one study each time and repeating the analysis [32]. All analyses were conducted in STATA statistical software (Version 12.0. STATA Corp., College Station, Texas, USA).

\section{Results}

The search strategy initially yielded 11,156 publications (Figure 1), of which 11 were included in the meta-analyses [15-20,22,23,33-35]. Nine results were included for the final meta-analysis that compared the dietary zinc intake in diabetic and non-diabetic subjects $[19,20,22,23,33,34]$. Meanwhile, six results were included in the meta-analysis that compared the concentration of zinc in whole blood in diabetic and non-diabetic subjects [1518,35]. The characteristics of the included studies are summarized in Table 1. 
Meta-analysis of dietary zinc intake and T2DM data: Four studies selected for the dietary zinc intake meta-analysis were carried out in western countries (England [33], Brazil [20,22] and Australia [23]) and two in eastern countries (Korea [34] and Iraq [19]). All those studies had cross-sectional design $[20,22,23,33,34]$, except a clinical trial performed by Al-Maroof and Al-Sharbatti in Iraq [19]. However, data extracted for our systematic review and metaanalysis were collected at one time point, before intervention, so we were able to include baseline data from the study of Al-Maroof and Al-Sharbatti. Dietary zinc intake was determined using two different survey methods, 24-hour dietary recall, used by both studies from western countries [19,34], and dietary record administered for two [23], three [22], four [20] or seven [33] days. Two studies recruited only women [23,34], while the other studies collected data in men and women $[19,20,22,33]$. Known duration of diabetes was $7.20 \pm 7.26$ years for diabetic participants, taking into account five of the six selected studies $[19,20,22,23,34]$.

Meta-analysis of the concentration of zinc in whole blood and T2DM: Two studies selected for this meta-analysis (Table 2) were conducted in western countries (Austria [17] and Italy [18]), and three in eastern countries (Pakistan [15,35] and China [16]). Their design was cross-sectional, and the laboratory method used for tissue zinc analysis was AAS [15,17,35] or ICP-MS or ICP-AES $[16,18]$. The time since diagnosis of T2DM in patients ranged from 8 to 20 years. The quality of selected studies was moderate, according to the STROBE Statement [26].

An overall pooled MD of -0.40 (95\% Cl: -1.59 to 0.79$)$ was observed in the meta-analysis that investigated the dietary zinc intake in diabetic cases and healthy controls (Figure S1). Differences become significant (MD $=-2.26$; $95 \% \mathrm{Cl}$ : -3.49 to -1.02$)$ when diabetes was associated with complications (Figure 2). Moderate heterogeneity was observed in this meta-analysis $\left(\mathrm{I}^{2}=61.0 \%, \mathrm{P}=0.009\right)$, suggesting that $61 \%$ of the variability between studies was due to differences in dietary zinc intake and $29 \%$ due to sampling variation. To examine how much of the heterogeneity was accounted for by the presence of complications associated with diabetes, we used the adjusted $\mathrm{R}^{2}$ (Tabla 2 ), and observed that this explained heterogeneity largely $\left(R^{2}=92.20 \%\right.$; $I^{2}$ residual $\left.=0.00 \%\right)$. Thus, when we stratified by the presence of complications associated with diabetes, we observed that heterogeneity was reduced to $0.0 \%$ in the group without complications, and to $11.9 \%$ in the group with complications (Figure 2). In addition to complications associated with diabetes, duration of diabetes contributed significantly to the heterogeneity $\left(R^{2}=100.00 \% ; I^{2}\right.$ residual $\left.=0.00 \%\right)$. Through meta-regression (Figure 3), we found that for each year since the diagnosis of diabetes the mean difference in dietary zinc intake between diabetics and non-diabetics 
subjects seemed to increase $[\mathrm{MD}$ (dietary zinc intake $)=1.67+(-0.37) \times($ duration of diabetes in years)].

In the meta-analysis that compared the concentrations of zinc in whole blood in diabetic and non-diabetic subjects, a pooled MD of -216.80 (95\% Cl: -359.42 to -74.19$)$ was found (Figure S2). High heterogeneity was found in this meta-analysis $\left(I^{2}=97.7 \%, P<0.001\right)$. However, stratified analyses by geographic area, western vs. eastern countries, reduced considerably the heterogeneity $\left(\mathrm{I}^{2}=47.1 \%, \mathrm{P}<0.129\right)$ and $\left(\mathrm{I}^{2}=69.3 \%, \mathrm{P}<0.071\right)$, respectively (Figure 4). Identical results were obtained when we stratified by studies which had been matched by age vs. not matched by age (Figure S3), had similar aged groups in cases and controls vs. those which had different ages groups (Figure S4), and with sample size higher vs. lower than 150 participants (Figure S5). Furthermore, these stratified analysis explained $96.24 \%$ of heterogeneity $\mathrm{R}^{2}=96.24 \%$; ${ }^{2}$ residual $=55.19 \%$ ). In this metaanalysis, duration of diabetes had also an important influence on heterogeneity $\left(R^{2}=\right.$ $96.16 \% ; I^{2}$ residual $\left.=58.23 \%\right)$. We have also observed that for each year since the diagnosis of diabetes, the concentration of zinc in whole blood $(1 \mu \mathrm{g} / \mathrm{dL}=0.0483 \mu \mathrm{mol} / \mathrm{L})$ is reduced in diabetic patients regarding healthy controls. This data is presented as a bubble plot (Figure 5), and expressed in the equation of the regression line [MD (concentration of zinc in blood $)=732.61+(-77.88303) \times($ duration of diabetes in years) $]$. Finally, sample size also had an impact on the results (Figure 6) [MD (concentration of zinc in whole blood) $=$ $371.84+(-3.44) \times($ sample size $)]$.

By visual inspection, an overall symmetry of the funnel plots was observed for all metaanalyses (Figures S6 and S7). This was confirmed by the Egger's ( $P=0.553$ for metaanalysis of dietary zinc intake, and $P=0.768$ for meta-analysis of the concentration of zinc in whole blood) and Begg's ( $P=1.000$ for both meta-analyses) tests which were not significant, indicating the absence of publication bias. In addition, neither of the two meta-analyses results were affected substantially after removing one study at a time and repeating the analysis. The combined result ranged between -0.70 (95\% $\mathrm{Cl}:-1.87$ to 0.46$)$, after removing the result of Rauscher et al. [33] in men, and -0.08 (95\% Cl: -1.35 to 1.19$)$, after removing the study of Lee et al. [34] for the meta-analysis of dietary zinc intake. Meanwhile, for the meta-analysis of the concentration of zinc in whole blood, results ranged between -187.76 (95\% Cl: -344.87 to -30.65$)$, after removing the result of Kazi in women, and -264.86 (95\% Cl: -389.79 to -139.93$)$, after removing the study of Ekmekcioglu [17].

\section{Discussion and Conclusion}

Data from this systematic review, meta-analysis and meta-regression of observational studies suggests that there are significant differences in the concentration of zinc in whole 
blood between diabetic patients and healthy subjects. In addition, the duration of diabetes appears to be associated with the concentration of zinc in whole blood, which is not explained by a lower of dietary zinc intake in diabetic patients. Only when T2DM is associated with complications, such as diabetic nephropathy in which dietary therapy is essential, differences in dietary zinc intake became significant. Changes in the concentration of zinc in whole blood may reflect changes in tissue zinc distribution and cellular zinc homeostasis in patients with diabetes, as was suggested by Chausmer in 1998 [36].

Our results did not show significant differences in dietary zinc intake between diabetic and non-diabetic subjects. However, the combined result showed some evidence of heterogeneity $\left(I^{2}=61.0 \%\right)$. When we stratified by the presence of complications associated with diabetes, we found significant differences in the subgroup with complications (MD = 2.26; $95 \% \mathrm{Cl}:-3.49$ to -1.02$)$, and low heterogeneity $\left(\mathrm{I}^{2}=11.9 \%\right)$. Meanwhile, in the subgroup without complications no significant differences in dietary zinc intake between groups, and an undetectable heterogeneity $\left(I^{2}=0.0 \%\right)$ were found (Table 2$)$. Only two studies reported complications associated to T2DM in diabetic participants [20,34]. The study of Batista et al. was conducted on diabetic subjects with chronic kidney disease due mainly to diabetic nephropathy [20]. Meanwhile, Lee et al. reported that only $24.0 \%$ of T2DM cases did not have associated complications, 36.0\% presented diabetic nephropathy, and $10 \%$ coronary heart disease [34]. In patients with diabetic nephropathy, diet therapies, such as protein restriction are commonly advised $[37,38]$. It is well known that zinc intake correlates directly with protein intake, as these two nutrients share the same food sources [39]. This correlation was also observed in the study carried out by Batista et al. [20], supporting the role of advanced kidney disease as a cause of a lower dietary zinc intake in this patients. The change from not having to having complications associated with diabetes supposes a significant increment in MD of dietary zinc intake of $2.70 \mathrm{mg} /$ day (MD = -2.70; $95 \% \mathrm{Cl}:-4.48$ to $-0.93 ; \mathrm{P}=0.009$ ). Thus, diabetic patients consume $2.70 \mathrm{mg} /$ day less zinc than healthy controls when they have associated pathologies (Table 2).

The duration of diabetes seems to have an influence on dietary zinc intake. We observed that stratified analysis by duration of diabetes ( $<8 ; \geq 8$ years) and $(<5 ; 5-8 ; \geq 8$ years) reduced the heterogeneity considerably. In addition, when we conducted a meta-regression, introducing duration of diabetes as a continuous variable, we found that for each year since the diagnosis of T2DM, diabetics consume less zinc [MD (dietary zinc intake) $=1.67+(-$ 0.37) $x$ (duration of diabetes in years)] in their diet (Figure 3). However, this may be due to the inclusion of the studies where the diabetic patients had complications as described above. When these studies are excluded, no significant relationship or trend between the 
duration of diabetes and the MD of dietary zinc intake was observed $(\mathrm{MD}=0.07 ; 95 \% \mathrm{Cl}$ : 2.79 to $2.94, P=0.924)$.

Variables, such as gender, geographic area, age or BMI, do not appear to have an impact on the results (Table 2), suggesting that dietary zinc intake is similar in diabetic and nondiabetic subjects in all age ranges, in both genders, in normal weight or overweight, and in different populations.

For all the above, the dietary zinc intake does not seem to explain the observed differences in the concentration of zinc in whole blood between diabetic and non-diabetic individuals. However, these differences (Figure S2) may not be reliable due to the very high heterogeneity observed $\left(I^{2}=97.7 \%\right)$. Stratified analysis by geographic area (Figure 4$)$, as well as, matched controls (Figure S3), older group (Figure S4) or sample size (Figure S5), significantly reduced the heterogeneity to $47.1 \%$ and $69.3 \%$ in each subgroup (Table 3 ), demonstrating their influence on the differences in the concentration of zinc in whole blood, and making the result more plausible.

We have also observed significant differences in the concentration of zinc in whole blood between cases and controls, but only in eastern countries (Figure 4), namely China [16] and Pakistan [15,35] (table 3). Studies conducted in Austria [17] and Italy [18], did not show significant differences in the concentration of zinc in whole blood between cases and controls. Studies from eastern countries compared diabetic patients with age-matched healthy controls, whereas, studies from western countries recruited patients and controls with significantly different ages, which may explain differences in results found according to the geographic area.

The influence of the duration of diabetes on the concentration of zinc in whole blood has also been examined (Figure 5). The results revealed that for each year since the onset of T2DM, the concentration of zinc in whole blood decreases compared to healthy subjects. This result is consistent with study conducted by Luo et al., who found that duration of diabetes was a key determinant of serum zinc levels [40], suggesting that the duration of diabetes may be associated with changes in zinc homeostasis. Drug therapy in diabetic patients could play a key role in the relationship between the duration of diabetes and the concentration of zinc in whole blood. Thus, it has been proposed that insulin treatment may normalised the tissue zinc concentration [9]. Unfortunately, this premise could not be assessed in our meta-analysis since data from selected studies was insufficient. Only two studies reported the use of insulin therapy in 40\% [15] and 100\% [35] of diabetic participants, and their whole blood zinc concentrations were significantly lower compared to 
healthy controls. These data do not support the hypothesis, but further studies are needed to explore this in more detail.

Some limitations to our study need to be considered. First, the relatively small number of studies included in both meta-analyses, despite the large number of articles obtained from the search $(11,156)$. This is because the robust search strategy within the framework of the EURRECA Network of Excellence was conducted as part of a wider review process to identify studies assessing the effect of zinc on different outcomes, and was designed to avoid publication bias. In addition, we included non-English language journals, reducing any potential bias. Furthermore, standard tests and visual inspection of funnel plots in both metaanalyses suggest that there is little evidence for publication bias. Second, the quality of the selected studies was moderate, according to the STROBE Statement [26]. After evaluating the influence of quality on results through stratified analyses and meta-regression, no significant impact on the effect size was observed in any of the meta-analyses. Furthermore, when the highest quality studies were combined to obtain a pooled MD, there was no detectable heterogeneity in either meta-analysis $(0.0 \%)$, and the results were similar to the respective overall pooled MD (Tables 2 and 3). Third, since the overall analyses did not have a large sample size, the stratified analyses might have insufficient power to detect potential sources of heterogeneity. In order to correct this, we carried out, not only stratified analysis, but also random effects meta-regressions to examine whether any covariate had influence on the results. Fourth, the results showed an undetectable to moderate heterogeneity in both meta-analyses (Figures 2 and 4), which also contribute to the study validity. Finally, none of the selected studies for meta-analysis of zinc concentration reported whether or not the samples were collected from fasting participants. This could be a source of bias, however it is noteworthy that all the selected studies for this meta-analysis used whole blood samples to measure zinc concentration, thus avoiding possible biases caused by using different samples.

The relationship between zinc and glucose metabolism has been evidenced in numerous studies. Zinc participates in the synthesis, storage, secretion, action of insulin and translocation of insulin into the cells [1-3], as well as translocation of GLUT4 to the cell surface for glucose transport into the insulin responsive cells [4]. However, the underlying biological mechanism whereby T2DM could have an impact on zinc homeostasis has not been elucidated. Recently, the importance of the cellular zinc transport system in T2DM has been highlighted $[41,42]$. A study conducted by Chu et al., found differences in gene expressions for most zinc transporters analysed, such as ZnT1, ZnT5, ZnT7, ZIP1, ZIP3, ZIP7, ZIP10, metallothionein-1A and metallothionein-2A. A lower gene expression in all these transporters was observed in diabetics compared to controls, suggesting disturbances 
T2DM-associated zinc dyshomeostasis at the cellular level [11]. This alteration on zinc metabolism may explain differences in the concentration of zinc in whole blood in diabetic subjects observed in the present systematic review, meta-analysis and meta-regression. Nevertheless, the preliminary results of another systematic review and meta-analysis of more than 73 papers conducted by our group reveals a lack of significant difference in zinc status, measured using serum or plasma zinc concentration, between diabetic patients and healthy controls. A possible explanation to both results could be that T2DM may not induce a lower zinc status compared with non-diabetic subjects, but has a negative impact on zinc homeostasis that would lead to differences in tissue zinc concentrations, such as blood. In conclusion, data from this systematic review, meta-analysis and meta-regression of observational studies suggests that there are significantly lower concentration of zinc in whole blood of diabetic patients compared with non-diabetic subjects, which is not explained by lower dietary zinc intakes. Only when T2DM is associated with complications, such as diabetic nephropathy, in which dietary therapy is essential, a lower dietary zinc intake is observed. However, the duration of diabetes could have a significant impact on whole blood zinc concentration. Additional research is required to elucidate the possible underpinning mechanisms.

\section{Acknowledgements}

This article is based upon work from COST Action TD1304 supported by COST (European Cooperation in Science and Technology).

\section{Declarations of interest}

None

\section{Funding}

This research did not receive any specific grant from funding agencies in the public, commercial, or not-for-profit sectors. 
Figure 1. Flowchart of the search for studies and the selection process.

Figure 2. Forest plot of pooled mean difference of dietary zinc intake according to the presence of complications associated to diabetes. Squares represent the mean difference (MD) for each study and the size of the square reflects the study-specific statistical weight. Horizontal lines indicate the $95 \% \mathrm{Cl}$ of each study. Diamond represents the combined MD estimate with corresponding $95 \% \mathrm{Cl}$. I-squared and p-value inform about heterogeneity among studies.

Figure 3. Bubble plot with a fitted meta-regression line of the mean difference in dietary zinc intake and duration of diabetes. Circles are sized according to the precision of each estimate (the inverse of its within-study variance) with larger bubbles for more precise estimates.

Figure 4. Forest plot of pooled mean difference of concentration of zinc in whole blood according to geographic area. Squares represent the mean difference (MD) for each study and the size of the square reflects the study-specific statistical weight. Horizontal lines indicate the $95 \% \mathrm{Cl}$ of each study. Diamond represents the combined MD estimate with corresponding $95 \% \mathrm{Cl}$. I-squared and p-value inform about heterogeneity among studies.

Figure 5.Bubble plot with a fitted meta-regression line of the mean difference in concentration of zinc in whole blood and duration of diabetes. Circles are sized according to the precision of each estimate (the inverse of its within-study variance) with larger bubbles for more precise estimates.

Figure 6. Bubble plot with a fitted meta-regression line of the mean difference in concentration of zinc in whole blood and sample size of the studies. Circles are sized according to the precision of each estimate (the inverse of its within-study variance) with larger bubbles for more precise estimates. 


\section{Appendix A. Supplementary data}

Table S1. Evaluation of the quality based on the STROBE Statement.

Figure S1. Forest plot of pooled mean difference of dietary zinc intake. Squares represent the mean difference (MD) for each study and the size of the square reflects the studyspecific statistical weight. Horizontal lines indicate the $95 \% \mathrm{Cl}$ of each study. Diamond represents the combined MD estimate with corresponding $95 \% \mathrm{Cl}$. I-squared and p-value inform about heterogeneity among studies.

Figure S2. Forest plot of pooled mean difference of concentration of zinc in whole blood. Squares represent the mean difference (MD) for each study and the size of the square reflects the study-specific statistical weight. Horizontal lines indicate the $95 \% \mathrm{Cl}$ of each study. Diamond represents the combined MD estimate with corresponding $95 \% \mathrm{CI}$. Isquared and p-value inform about heterogeneity among studies.

Figure S3. Forest plot of pooled mean difference of concentration of zinc in whole blood according to control matched (No matched, matched by age). Squares represent the mean difference (MD) for each study and the size of the square reflects the study-specific statistical weight. Horizontal lines indicate the $95 \% \mathrm{Cl}$ of each study. Diamond represents the combined MD estimate with corresponding $95 \% \mathrm{Cl}$. I-squared and p-value inform about heterogeneity among studies.

Figure S4. Forest plot of pooled mean difference of concentration of zinc in whole blood according to age in diabetic and non-diabetic groups (same age, different age). Squares represent the mean difference (MD) for each study and the size of the square reflects the study-specific statistical weight. Horizontal lines indicate the $95 \% \mathrm{Cl}$ of each study. Diamond represents the combined MD estimate with corresponding $95 \% \mathrm{Cl}$. I-squared and p-value inform about heterogeneity among studies.

Figure S5. Forest plot of pooled mean difference of concentration of zinc in whole blood according to sample size $(<150,>150)$. Squares represent the mean difference (MD) for 
each study and the size of the square reflects the study-specific statistical weight. Horizontal lines indicate the $95 \% \mathrm{Cl}$ of each study. Diamond represents the combined MD estimate with corresponding $95 \% \mathrm{Cl}$. I-squared and p-value inform about heterogeneity among studies.

Figure S6. Funnel plots of publication biases of studies included in the meta-analysis of dietary zinc intake. Y-axis stands for the standard error of the mean difference of dietary zinc intake and X-axis stands for the mean difference of dietary zinc intake. Each dot stands for an individual study. Asymmetric funnel plot indicates a publication bias.

Figure S7. Funnel plots of publication biases of studies included in the meta-analysis of concentration of zinc in whole blood. Y-axis stands for the standard error of the mean difference of concentration of zinc in whole blood and X-axis stands for the mean difference of concentration of zinc in whole blood. Each dot stands for an individual study. Asymmetric funnel plot indicates a publication bias. 


\section{References:}

[1] S.R. Keller, Role of the insulin-regulated aminopeptidase IRAP in insulin action and diabetes, Biol. Pharm. Bull. 27 (2004) 761-764.

[2] J.A. Meyer, D.M. Spence, A perspective on the role of metals in diabetes: past findings and possible future directions, Metallomics. 1 (2009) 32-41.

[3] W.T. Moore, S.M. Bowser, D.W. Fausnacht, L.L. Staley, K.-S. Suh, D. Liu, Beta Cell Function and the Nutritional State: Dietary Factors that Influence Insulin Secretion, Curr. Diab. Rep. 15 (2015) 76.

[4] X. Tang, N.F. Shay, Zinc has an insulin-like effect on glucose transport mediated by phosphoinositol-3-kinase and Akt in 3T3-L1 fibroblasts and adipocytes, J. Nutr. 131 (2001) 1414-1420.

[5] Q. Sun, R.M. Van Dam, W.C. Willett, F.B. Hu, Prospective study of zinc intake and risk of type 2 diabetes in women, Diabetes Care. 32 (2009) 629-634.

[6] A. Chu, M. Foster, S. Samman, Zinc status and risk of cardiovascular diseases and type 2 diabetes mellitus--A systematic review of prospective cohort studies, Nutrients. 8 (2016) 1-19.

[7] K. Jurowski, B. Szewczyk, G. Nowak, W. Piekoszewski, Biological consequences of zinc deficiency in the pathomechanisms of selected diseases, J. Biol. Inorg. Chem. 19 (2014) 1069-1079.

[8] P. Ranasinghe, S. Pigera, P. Galappatthy, P. Katulanda, G.R. Constantine, Zinc and diabetes mellitus: understanding molecular mechanisms and clinical implications., Daru. 23 (2015) 44.

[9] J. Jansen, W. Karges, L. Rink, Zinc and diabetes--clinical links and molecular mechanisms., J. Nutr. Biochem. 20 (2009) 399-417.

[10] V. da S. Bandeira, L.V. Pires, L.L. Hashimoto, L.L. de Alencar, K.G.S. Almondes, S.A. Lottenberg, S.M.F. Cozzolino, Association of reduced zinc status with poor glycemic control in individuals with type 2 diabetes mellitus, J. Trace Elem. Med. Biol. 44 (2017) $132-136$.

[11] A. Chu, M. Foster, D. Hancock, P. Petocz, S. Samman, Interrelationships among mediators of cellular zinc homeostasis in healthy and type 2 diabetes mellitus populations, Mol. Nutr. Food Res. 61 (2017). 
[12] R. Jayawardena, P. Ranasinghe, P. Galappatthy, R. Malkanthi, G. Constantine, P. Katulanda, Effects of zinc supplementation on diabetes mellitus: a systematic review and meta-analysis, Diabetol. Metab. Syndr. 4 (2012) 13.

[13] S. Sinha, S. Sen, Status of zinc and magnesium levels in type 2 diabetes mellitus and its relationship with glycemic status, Int. J. Diabetes Dev. Ctries. 34 (2014) 220-223.

[14] International Diabetes Federation (IDF), IDF Diabetes Atlas 7th edition, 2015.

[15] T.G. Kazi, H.I. Afridi, N. Kazi, M.K. Jamali, M.B. Arain, N. Jalbani, G.A. Kandhro, Copper, chromium, manganese, iron, nickel, and zinc levels in biological samples of diabetes mellitus patients, Biol. Trace Elem. Res. 122 (2008) 1-18.

[16] H. Chen, C. Tan, Prediction of type-2 diabetes based on several element levels in blood and chemometrics, Biol. Trace Elem. Res. 147 (2012) 67-74.

[17] C. Ekmekcioglu, C. Prohaska, K. Pomazal, I. Steffan, G. Schernthaner, W. Marktl, Concentrations of seven trace elements in different hematological matrices in patients with type 2 diabetes as compared to healthy controls., Biol. Trace Elem. Res. 79 (2001) 205-19.

[18] G. Forte, B. Bocca, A. Peruzzu, F. Tolu, Y. Asara, C. Farace, R. Oggiano, R. Madeddu, Blood metals concentration in type 1 and type 2 diabetics, Biol. Trace Elem. Res. 156 (2013) 79-90.

[19] R.A. Al-Maroof, S.S. Al-Sharbatti, Serum zinc levels in diabetic patients and effect of zinc supplementation on glycemic control of type 2 diabetics, Saudi Med. J. 27 (2006) 344-350.

[20] M.N. Batista, L. Cuppari, L. de Fátima Campos Pedrosa, M.D.G. Almeida, J.B. de Almeida, A.C.Q. de Medeiros, M.E.F. Canziani, Effect of end-stage renal disease and diabetes on zinc and copper status., Biol. Trace Elem. Res. 112 (2006) 1-12.

[21] N.M. Lowe, M.W. Medina, A.-L. Stammers, S. Patel, O.W. Souverein, C. Dullemeijer, L. Serra-Majem, M. Nissensohn, V. Hall Moran, The relationship between zinc intake and serum/plasma zinc concentration in adults: a systematic review and doseresponse meta-analysis by the EURRECA Network., Br. J. Nutr. 108 (2012) 1962-71.

[22] V.B. de S. Lima, F. de A. Sampaio, D.L.C. Bezerra, J.M. Moita Neto, D. do N. Marreiro, Parameters of glycemic control and their relationship with zinc concentrations in blood and with superoxide dismutase enzyme activity in type 2 diabetes patients., Arq. Bras. Endocrinol. Metabol. 55 (2011) 701-7. 
[23] M. Foster, M. Karra, T. Picone, A. Chu, D.P. Hancock, P. Petocz, S. Samman, Dietary fiber intake increases the risk of zinc deficiency in healthy and diabetic women, Biol. Trace Elem. Res. 149 (2012) 135-142.

[24] D.F. Stroup, J.A. Berlin, S.C. Morton, I. Olkin, G.D. Williamson, D. Rennie, D. Moher, B.J. Becker, T.A. Sipe, S.B. Thacker, Meta-analysis of observational studies in epidemiology: a proposal for reporting. Meta-analysis Of Observational Studies in Epidemiology (MOOSE) group., in: JAMA, 2000: pp. 2008-2012.

[25] X. Wan, W. Wang, J. Liu, T. Tong, Estimating the sample mean and standard deviation from the sample size, median, range and/or interquartile range., BMC Med. Res. Methodol. 14 (2014) 135.

[26] E. von Elm, D.G. Altman, M. Egger, S.J. Pocock, P.C. Gøtzsche, J.P. Vandenbroucke, The Strengthening the Reporting of Observational Studies in Epidemiology (STROBE) statement: guidelines for reporting of observational studies, in: Internist (Berl)., 2008: pp. 688-693.

[27] T.B. Huedo-Medina, J. Sánchez-Meca, F. Marín-Martínez, J. Botella, Assessing heterogeneity in meta-analysis: Q statistic or 12 index?, Psychol. Methods. 11 (2006) 193-206.

[28] J.P.T. Higgins, S.G. Thompson, Quantifying heterogeneity in a meta-analysis, Stat. Med. 21 (2002) 1539-1558.

[29] J.P.T. Higgins, S.G. Thompson, J.J. Deeks, D.G. Altman, Measuring inconsistency in meta-analyses, BMJ Br. Med. J. 327 (2003) 557-560.

[30] M. Egger, G. Davey Smith, M. Schneider, C. Minder, Bias in meta-analysis detected by a simple, graphical test., BMJ. 315 (1997) 629-634.

[31] C.B. Begg, M. Mazumdar, Operating Characteristics of a Rank Correlation Test for Publication Bias, Biometrics. 50 (1994) 1088.

[32] N.A. Patsopoulos, E. Evangelou, J.P.A. Ioannidis, Sensitivity of between-study heterogeneity in meta-analysis: Proposed metrics and empirical evaluation, Int. J. Epidemiol. 37 (2008) 1148-1157.

[33] A.M. Rauscher, S.J. Fairweather-Tait, P.D.G. Wilson, S. Gorrick, R. Greenwood, Zinc metabolism in non-insulin dependent diabetes mellitus, J. Trace Elem. Med. Biol. 11 (1997) 65-70.

[34] Y.J. Lee JH, Lee HJ, Lee IK, Zinc and copper status of middle- and old-aged woman 
in type 2 diabetes, Korean J. Nutr. 38 (2005) 56-66.

[35] H.I. Afridi, T.G. Kazi, N. Kazi, J.A. Baig, M.K. Jamali, M.B. Arain, R.A. Sarfraz, H.U.R. Sheikh, G.A. Kandhro, A.Q. Shah, Status of essential trace metals in biological samples of diabetic mother and their neonates, Arch. Gynecol. Obstet. 280 (2009) 415-423.

[36] A.B. Chausmer, Zinc, insulin and diabetes, J. Am. Coll. Nutr. 17 (1998) 109-115.

[37] S. Kume, D. Koya, T. Uzu, H. Maegawa, Role of nutrient-sensing signals in the pathogenesis of diabetic nephropathy, Biomed Res. Int. 2014 (2014).

[38] C. Dow, F. Mancini, K. Rajaobelina, M.-C. Boutron-Ruault, B. Balkau, F. Bonnet, G. Fagherazzi, Diet and risk of diabetic retinopathy: a systematic review, Eur. J. Epidemiol. (2017).

[39] J.C. Burge, R.A. Schemmel, H.S. Park, J.A. Greene lii, Taste acuity and zinc status in chronic renal disease, J. Am. Diet. Assoc. 84 (1984) 1203-1209.

[40] Y.-Y. Luo, J. Zhao, X.-Y. Han, X.-H. Zhou, J. Wu, L.-N. Ji, Relationship Between Serum Zinc Level and Microvascular Complications in Patients with Type 2 Diabetes, Chin. Med. J. (Engl). 128 (2015) 3276.

[41] M. Tamaki, Y. Fujitani, A. Hara, T. Uchida, Y. Tamura, K. Takeno, M. Kawaguchi, T. Watanabe, T. Ogihara, A. Fukunaka, T. Shimizu, T. Mita, A. Kanazawa, M.O. Imaizumi, T. Abe, H. Kiyonari, S. Hojyo, T. Fukada, T. Kawauchi, S. Nagamatsu, T. Hirano, R. Kawamori, H. Watada, The diabetes-susceptible gene SLC30A8/ZnT8 regulates hepatic insulin clearance, J. Clin. Invest. 123 (2013) 4513-4524.

[42] S.A. Myers, A. Nield, G.-S. Chew, M.A. Myers, The Zinc Transporter, Slc39a7 (Zip7) Is Implicated in Glycaemic Control in Skeletal Muscle Cells, PLoS One. 8 (2013). 
11.150 Citations identified from Ovid MEDLINE, Embase (Ovid) and The Cochrane Library (CENTRAL)

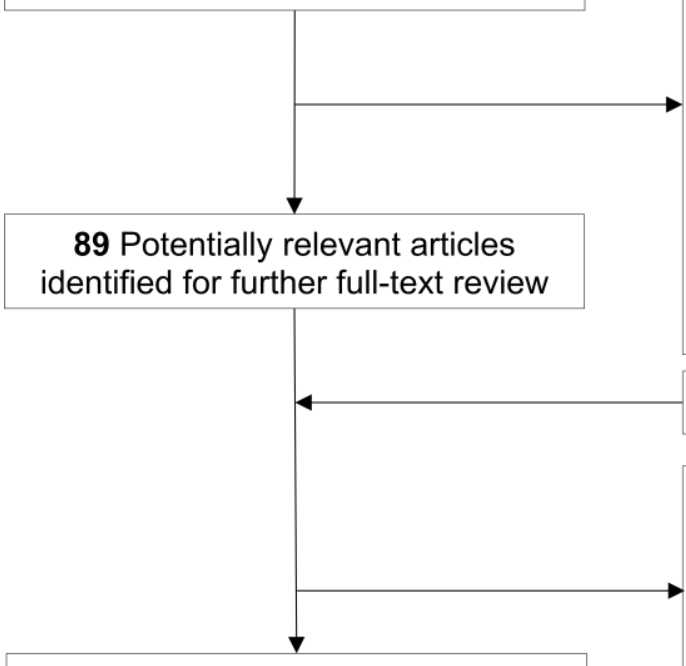

11 Articles in meta-analysis with data of dietary zinc intake and/or whole blood zinc concentration
11.061 Citations excluded after the full-text screening of titles or abstracts using general criteria: 1621 Children

411 Without data of zinc intake/whole blood zinc levels 5586 Without diabetics subjects

34 Diabetes other than type 2 diabetes mellitus 700 Design other than observational

70 Animal or lab studies

672 Don't analyse the relationship 1967 Duplicate

\section{Article identified from manual screening}

84 Articles excluded after the full-text screening: 15 Without data of zinc intake/whole blood zinc levels 3 Without diabetics 3 Studying other types of diabetes 11 Other study design

52 Don't evaluate the association 
Table 1. Characteristics of studies included in the meta-analyses and meta-regressions on dietary zinc intake and whole blood zinc concentration in diabetic and non-diabetic subjects.

\begin{tabular}{|c|c|c|c|c|c|c|c|c|c|c|c|}
\hline Author, year & Location & Gender & $\begin{array}{l}\text { Age (years) in } \\
\text { diabetic subjects } \\
\text { (Mean } \pm \text { SD) }\end{array}$ & $\begin{array}{l}\text { Age (years) in non- } \\
\text { diabetic subjects } \\
\text { (Mean } \pm \text { SD) }\end{array}$ & $\begin{array}{l}\text { Sample } \\
\text { size }\end{array}$ & $\begin{array}{l}\text { T2DM } \\
\text { (n) }\end{array}$ & $\begin{array}{l}\text { Control } \\
\text { Matched }\end{array}$ & $\begin{array}{l}\text { T2DM duration in } \\
\text { years (Mean } \pm S D \text { ) }\end{array}$ & $\begin{array}{l}\text { Zinc assessment } \\
\text { method }\end{array}$ & $\begin{array}{c}\text { Dietary }(\mathrm{mg} / \text { day }) \\
\text { or whole blood } \\
(\mu \mathrm{mol} / \mathrm{L}) \text { zinc in } \\
\text { diabetics } \\
(\text { Mean } \pm S D)\end{array}$ & $\begin{array}{c}\text { Dietary (mg/day) } \\
\text { or whole blood } \\
\text { ( } \mu \text { mol/L) zinc in } \\
\text { non-diabetics } \\
\text { (Mean } \pm S D)\end{array}$ \\
\hline \multicolumn{12}{|c|}{ Studies of dietary zinc intake } \\
\hline \multirow{3}{*}{ Rauscher, 1997} & \multirow{3}{*}{ England } & $\begin{array}{l}\text { Women } \\
\text { / Men }\end{array}$ & $\begin{array}{c}\text { Range: } 49-72 \\
63.0\end{array}$ & Range: 50-77 & 20 & 10 & \multirow{3}{*}{$\begin{array}{l}\text { Age, sex \& } \\
\text { weight }\end{array}$} & \multirow{3}{*}{ Not Showed } & \multirow{3}{*}{ 7-day dietary record } & $11.8 \pm 2.2$ & $10.3 \pm 2.6$ \\
\hline & & Men & $\begin{array}{l}\text { Range: } 49-71 \\
61.0\end{array}$ & Range: 50-71 & 10 & 5 & & & & $13.2 \pm 1.5$ & $11.1 \pm 2.5$ \\
\hline & & Women & $\begin{array}{c}\text { Range: } 60-72 \\
65.0\end{array}$ & $\begin{array}{c}\text { Range: } 60-77 \\
65.0\end{array}$ & 10 & 5 & & & & $10.3 \pm 1.8$ & $9.5 \pm 2.5$ \\
\hline Lee, 2005 & Korea & Women & $57.9 \pm 6.9$ & $56.3 \pm 7.9$ & 119 & 50 & No & $8.0 \pm 6.5$ & 24h-hour recall & $6.2 \pm 2.7$ & $8.0 \pm 3.2$ \\
\hline Al-Maroof, 2006 & Iraq & $\begin{array}{l}\text { Women } \\
\text { / Men }\end{array}$ & $54.6 \pm 9.2$ & $39.0 \pm 9.3$ & 234 & 101 & No & $5.1 \pm 6.0$ & 24h-hour recall & $12.2 \pm 4.6$ & $12.4 \pm 4.4$ \\
\hline \multirow{3}{*}{ Batista, 2006} & \multirow{3}{*}{ Brazil } & $\begin{array}{l}\text { Women } \\
\text { / Men }\end{array}$ & \multirow{3}{*}{$61.1 \pm 8.1$} & \multirow{3}{*}{$52.9 \pm 9.7$} & 53 & 33 & \multirow{3}{*}{ No } & \multirow{3}{*}{$16.3 \pm 8.8$} & \multirow{3}{*}{ 4-day dietary record } & $6.5 \pm 4.2$ & $9.4 \pm 5.0$ \\
\hline & & Men & & & 24 & 16 & & & & $7.5 \pm 3.8$ & $11.6 \pm 4.5$ \\
\hline & & Women & & & 29 & 17 & & & & $4.6 \pm 2.7$ & $8.1 \pm 5.2$ \\
\hline \multirow{2}{*}{$\begin{array}{l}\text { de Sousa Lima, } \\
\qquad 2011\end{array}$} & \multirow{2}{*}{ Brazil } & $\begin{array}{l}\text { Women } \\
\text { / Men }\end{array}$ & \multirow{2}{*}{ Range: $25-5946.0 \pm 7.4$} & \multirow{2}{*}{$37.2 \pm 8.6$} & 73 & 36 & \multirow{2}{*}{ No } & \multirow{2}{*}{$4.0 \pm 2.4$} & \multirow{2}{*}{ 3-day dietary record } & $12.9 \pm 5.8$ & $11.7 \pm 4.7$ \\
\hline & & Women & & & 51 & 24 & & & & $10.9 \pm 3.5$ & $10.5 \pm 3.4$ \\
\hline Foster, 2012 & Australia & Women & $\begin{array}{c}\text { Range: } 48.3-79 \\
63.8 \pm 8.8\end{array}$ & $\begin{array}{c}\text { Range: } 21.4-65.6 \\
39.4 \pm 13.8\end{array}$ & 40 & 20 & No & $6.5 \pm 5.2$ & 2-day dietary record & $12.8 \pm 5.3$ & $11.6 \pm 3.8$ \\
\hline \multicolumn{12}{|c|}{ Studies of concentrations of zinc in blood } \\
\hline Ekmekcioglu, 2001 & Austria & $\begin{array}{c}\text { Not } \\
\text { Showed }\end{array}$ & $63.8 \pm 11.0$ & $70.5 \pm 12.4$ & 103 & 53 & No & Not Showed & EAAS & $25.7 \pm 4.7$ & $24.9 \pm 5.8$ \\
\hline \multirow{3}{*}{ Kazi, 2008} & \multirow{3}{*}{ Pakistan } & $\begin{array}{l}\text { Women } \\
\text { / Men }\end{array}$ & \multirow{3}{*}{ Range: $45-75$} & \multirow{3}{*}{ Range: $45-75$} & 423 & 257 & \multirow{3}{*}{ Age } & \multirow{3}{*}{ Range: $8-20$} & \multirow{3}{*}{ AAS } & $31.3 \pm 10.6$ & $47.9 \pm 7.5$ \\
\hline & & Men & & & 217 & 137 & & & & $29.9 \pm 10.7$ & $46.9 \pm 7.2$ \\
\hline & & Women & & & 206 & 120 & & & & $32.7 \pm 10.4$ & $48.9 \pm 7.7$ \\
\hline Afridi, 2009 & Pakistan & Women & Range: 30-40 & Range: $30-40$ & 182 & 89 & Age & Range: 10-15 & F/EAAS & $46.9 \pm 6.3$ & $60.4 \pm 7.2$ \\
\hline Chen, 2012 & China & $\begin{array}{c}\text { Not } \\
\text { Showed }\end{array}$ & Range: $25->50$ & Range: $25->50$ & 158 & 53 & Age & Not Showed & ICP- AES & $43.1 \pm 31.4$ & $60.4 \pm 48.3$ \\
\hline Forte, 2013 & Italy & $\begin{array}{l}\text { Women } \\
\text { / Men }\end{array}$ & Mean $\pm S D: 68.4 \pm 11.2$ & Mean $\pm S D: 57.2 \pm 18.0$ & 127 & 68 & No & $\begin{array}{l}\text { Mean } \pm \text { SD: } \\
10.2 \pm 8.6\end{array}$ & ICP-MS & $30.5 \pm 4.8$ & $32.6 \pm 8.2$ \\
\hline
\end{tabular}

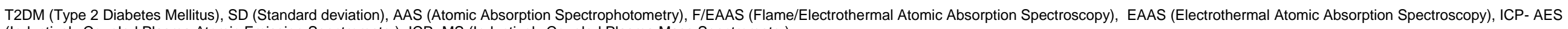
(Inductively Coupled Plasma Atomic Emission Spectrometry), ICP-MS (Inductively Coupled Plasma Mass Spectrometry). 
Table 2. Stratified analysis and meta-regression for mean difference of dietary zinc intake in diabetic and non-diabetic subjects.

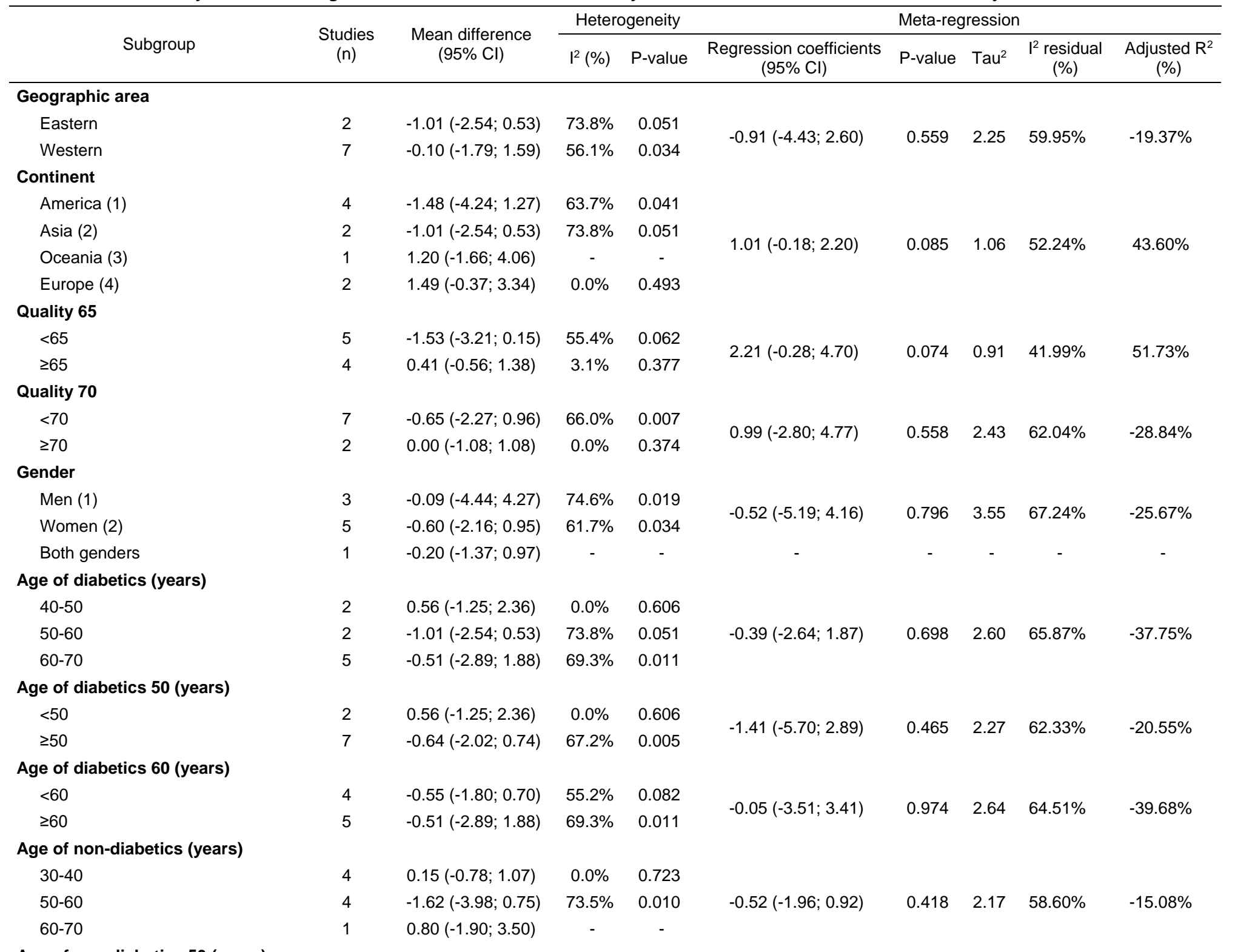




\begin{tabular}{|c|c|c|c|c|c|c|c|c|c|}
\hline$<50$ & 4 & $0.15(-0.78 ; 1.07)$ & $0.0 \%$ & 0.723 & \multirow{2}{*}{$-1.57(-4.65 ; 1.51)$} & \multirow{2}{*}{0.267} & \multirow{2}{*}{1.86} & \multirow{2}{*}{$54.22 \%$} & \multirow{2}{*}{$1.61 \%$} \\
\hline$\geq 50$ & 5 & $-1.13(-3.16 ; 0.89)$ & $71.4 \%$ & 0.007 & & & & & \\
\hline \multicolumn{10}{|c|}{ Age difference between diabetics and non-diabetics (years) } \\
\hline$<5$ & 3 & $0.16(-2.43 ; 2.76)$ & $78.7 \%$ & 0.009 & \multirow{3}{*}{$0.02(-2.15 ; 2.20)$} & \multirow{3}{*}{0.982} & \multirow{3}{*}{2.70} & \multirow{3}{*}{$62.83 \%$} & \multirow{3}{*}{$-43.24 \%$} \\
\hline $5-15$ & 4 & $-1.48(-4.24 ; 1.27)$ & $63.7 \%$ & 0.041 & & & & & \\
\hline$\geq 15$ & 2 & $0.00(-1.08 ; 1.08)$ & $0.0 \%$ & 0.374 & & & & & \\
\hline \multicolumn{10}{|c|}{ Age difference between diabetics and non-diabetics II (years) } \\
\hline$<10$ & 7 & $-0.65(-2.27 ; 0.96)$ & $66.0 \%$ & 0.007 & \multirow{2}{*}{$0.99(-2.80 ; 4.77)$} & \multirow{2}{*}{0.558} & \multirow{2}{*}{2.43} & \multirow{2}{*}{$62.04 \%$} & \multirow{2}{*}{$-28.84 \%$} \\
\hline$\geq 10$ & 2 & $0.00(-1.08 ; 1.08)$ & $0.0 \%$ & 0.374 & & & & & \\
\hline \multicolumn{10}{|l|}{ Older group } \\
\hline Same age (1) & 3 & $0.16(-2.43 ; 2.76)$ & $78.7 \%$ & 0.009 & \multirow{2}{*}{$-0.76(-4.26 ; 2.74)$} & \multirow{2}{*}{0.623} & \multirow{2}{*}{2.71} & \multirow{2}{*}{$64.32 \%$} & \multirow{2}{*}{$-43.85 \%$} \\
\hline Different age (2) & 6 & $-0.62(-2.12 ; 0.88)$ & $51.1 \%$ & 0.069 & & & & & \\
\hline \multicolumn{10}{|l|}{ BMI category in diabetics } \\
\hline Normal weight $\left(18.5-24.9 \mathrm{~kg} / \mathrm{m}^{2}\right)$ & 5 & $-1.13(-3.16 ; 0.89)$ & $71.4 \%$ & 0.007 & \multirow{2}{*}{$1.57(-1.51 ; 4.65)$} & \multirow{2}{*}{0.267} & \multirow{2}{*}{1.86} & & \\
\hline Overweight $\left(25.0-29.9 \mathrm{~kg} / \mathrm{m}^{2}\right)$ & 4 & $0.15(-0.78 ; 1.07)$ & $0.0 \%$ & 0.723 & & & & $54.22 \%$ & $1.61 \%$ \\
\hline BMI category in non-diabetics & & & & & & & & & \\
\hline Normal weight $\left(18.5-24.9 \mathrm{~kg} / \mathrm{m}^{2}\right)$ & 5 & $-0.03(-1.57 ; 1.51)$ & $55.1 \%$ & 0.064 & & & & & \\
\hline Overweight $\left(25.0-29.9 \mathrm{~kg} / \mathrm{m}^{2}\right)$ & 4 & $-1.10(-3.51 ; 1.30)$ & $73.6 \%$ & 0.010 & $-1.11(-4.47 ; 2.24)$ & 0.459 & 2.73 & $65.44 \%$ & $-44.77 \%$ \\
\hline Duration of diabetes (years) & & & & & & & & & \\
\hline$<8$ & 4 & $0.15(-0.78 ; 1.07)$ & $0.0 \%$ & 0.723 & 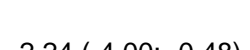 & 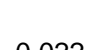 & 0 000 & ח0 & (19 \\
\hline$\geq 8$ & 3 & $-2.26(-3.49 ;-1.02)$ & $11.9 \%$ & 0.321 & $-2.24(-4.00 ;-0.48)$ & 0.022 & 0.00 & $0.00 \%$ & $100.00 \%$ \\
\hline No data & 2 & $1.49(-0.37 ; 3.34)$ & $0.0 \%$ & 0.493 & - & - & - & - & - \\
\hline Complications & & & & & & & & & \\
\hline Without complications of diabetes & 6 & $0.41(-0.41 ; 1.24)$ & $0.0 \%$ & 0.640 & & & & & ח0 \\
\hline With complications of diabetes & 3 & $-2.26(-3.49 ;-1.02)$ & $11.9 \%$ & 0.321 & $-2.70(-4.48 ;-0.93)$ & 0.009 & 0.15 & $0.00 \%$ & $92.20 \%$ \\
\hline Sample size & & & & & & & & & \\
\hline$<100$ & 7 & $-0.10(-1.79 ; 1.59)$ & $56.1 \%$ & 0.034 & $001+412.000$ & 0550 & 205 & 50050 & $10.270 \%$ \\
\hline$\geq 100$ & 2 & $-1.01(-2.54 ; 0.53)$ & $73.8 \%$ & 0.051 & $-0.91(-4.43 ; 2.60)$ & 0.559 & 2.25 & $59.95 \%$ & $-19.3 / \%$ \\
\hline Matched & & & & & & & & & \\
\hline No matched & 2 & $-0.89(-2.14 ; 0.36)$ & $58.1 \%$ & 0.026 & $020+1-10-01$ & & 110 & & \\
\hline Matched by age, gender \& weight & 7 & $1.49(-0.37 ; 3.34)$ & $0.0 \%$ & 0.493 & $2.36(-1.10 ; 5.81)$ & 0.151 & 1.10 & $52.69 \%$ & $42.20 \%$ \\
\hline Dietary survey method & & & & & & & & & \\
\hline 24-hour dietary recall & 2 & $-1.01(-2.54 ; 0.53)$ & $73.8 \%$ & 0.051 & & & & & \\
\hline Dietary record & 7 & $-0.10(-1.79 ; 1.59)$ & $56.1 \%$ & 0.034 & $0.91(-2.60 ; 4.43)$ & 0.559 & 2.25 & $59.95 \%$ & $-19.37 \%$ \\
\hline
\end{tabular}


24-hour dietary recall (1)

2-day dietary record (2)

3-day dietary record (3)

4-day dietary record (4)

7-day dietary record (7)

BMI (Body Mass Index).
2

$-1.01(-2.54 ; 0.53) \quad 73.8 \% \quad 0.051$

$1.20(-1.66 ; 4.06)$

$0.56(-1.25 ; 2.36)$

$0.0 \% \quad 0.606$

$0.26(-0.45 ; 0.97)$

$0.413 \quad 1.82 \quad 58.44 \%$

$3.60 \%$

$1.49(-0.37 ; 3.34) \quad 0.0 \% \quad 0.493$


Table 3. Stratified analysis for mean difference of the whole blood zinc concentration in diabetic and non-diabetic subjects.

\begin{tabular}{|c|c|c|c|c|c|c|c|c|c|}
\hline \multirow[b]{2}{*}{ Subgroup } & \multirow[b]{2}{*}{$\begin{array}{l}\text { Studies } \\
\text { (n) }\end{array}$} & \multirow[b]{2}{*}{ Mean difference $(95 \% \mathrm{Cl})$} & \multicolumn{2}{|c|}{ Heterogeneity } & \multicolumn{5}{|c|}{ Meta-regression } \\
\hline & & & $\mathrm{I}^{2}(\%)$ & $\begin{array}{c}\mathrm{P}- \\
\text { value }\end{array}$ & $\begin{array}{l}\text { Regression coefficients } \\
(95 \% \mathrm{Cl})\end{array}$ & P-value & $\mathrm{Tau}^{2}$ & $\begin{array}{l}I^{2} \text { residual } \\
(\%)\end{array}$ & $\begin{array}{c}\text { Adjusted } R^{2} \\
(\%)\end{array}$ \\
\hline \multicolumn{10}{|l|}{ Geographic area } \\
\hline Eastern & 4 & $-320.83(-361.46 ;-280.19)$ & $47.1 \%$ & 0.129 & \multirow{2}{*}{$-309.20(-408.99 ;-209.42)$} & \multirow{2}{*}{0.001} & \multirow{2}{*}{1012} & \multirow{2}{*}{$55.19 \%$} & \multirow{2}{*}{$96.24 \%$} \\
\hline Western & 2 & $-12.41(-70.89 ; 46.08)$ & $69.3 \%$ & 0.071 & & & & & \\
\hline \multicolumn{10}{|l|}{ Continent } \\
\hline Europe & 2 & $-12.41(-70.89 ; 46.08)$ & $69.3 \%$ & 0.071 & \multirow{2}{*}{$-309.20(-408.99 ;-209.42)$} & \multirow{2}{*}{0.001} & \multirow{2}{*}{1012} & \multirow{2}{*}{$55.19 \%$} & \multirow{2}{*}{$96.24 \%$} \\
\hline Asia & 4 & $-320.83(-361.46 ;-280.19)$ & $47.1 \%$ & 0.129 & & & & & \\
\hline \multicolumn{10}{|l|}{ Quality 50} \\
\hline$<50$ & 3 & $-191.61(-438.19 ; 54.97)$ & $98.0 \%$ & $<0.001$ & \multirow{2}{*}{$-55.64(-479.08 ; 367.81)$} & \multirow{2}{*}{0.734} & \multirow{2}{*}{32234} & \multirow{2}{*}{$97.94 \%$} & \multirow{2}{*}{$-19.72 \%$} \\
\hline$\geq 50$ & 3 & $-243.57(-440.95 ;-46.19)$ & $97.9 \%$ & $<0.001$ & & & & & \\
\hline \multicolumn{10}{|l|}{ Quality 55} \\
\hline$<55$ & 4 & $-146.24(-316.36 ; 23.89)$ & $97.3 \%$ & $<0.001$ & \multirow{2}{*}{$-202.89(-547.55 ; 141.77)$} & \multirow{2}{*}{0.178} & \multirow{2}{*}{18048} & \multirow{2}{*}{$96.42 \%$} & \\
\hline$\geq 55$ & 2 & $-343.86(-379.36 ;-308.37)$ & $0.0 \%$ & 0.649 & & & & & $32.96 \%$ \\
\hline Gender & & & & & & & & & \\
\hline Men (1) & 1 & $-351.80(-401.08 ;-302.52)$ & - & - & $46.41(-571.35 \cdot 644.17)$ & 0.515 & 972 & $63.59 \%$ & $0.18 \%$ \\
\hline Women (2) & 2 & $-305.39(-359.40 ;-251.38)$ & $63.6 \%$ & 0.097 & & & & & \\
\hline Both genders & 1 & $-43.73(-93.14 ; 5.67)$ & - & - & - & - & - & - & - \\
\hline No data & 2 & $-148.21(-512.01 ; 215.58)$ & $87.2 \%$ & $0.5 \%$ & - & - & - & - & - \\
\hline Age of diabetics (y & & & & & & & & & \\
\hline $30-40$ & 1 & $-280.00(-320.73 ;-239.27)$ & - & - & & & & & \\
\hline $50-60$ & 2 & $-343.86(-379.36 ;-308.37)$ & $0.0 \%$ & 0.649 & $88.59(-111.75 ; 288.93)$ & 0.254 & 23307 & $97.58 \%$ & $20.04 \%$ \\
\hline $60-70$ & 2 & $-12.41(-70.89 ; 46.08)$ & $69.3 \%$ & 0.071 & & & & & \\
\hline No data & 1 & $-358.00(-617.29 ;-98.71)$ & - & - & - & - & - & - & - \\
\hline Age of diabetics 5 & & & & & & & & & \\
\hline$<50$ & 1 & $-280.00(-320.73 ;-239.27)$ & - & - & $10157(-58072 \cdot 78386)$ & 0668 & 36305 & $98.3 \% \%$ & $-2455 \%$ \\
\hline$\geq 50$ & 4 & $-178.44(-369.42 ; 12.55)$ & $98.4 \%$ & $<0.001$ & $101.5 /(-580.12 ; 183.80)$ & 0.668 & 30305 & $98.43 \%$ & $-24.05 \%$ \\
\hline No data & 1 & $-358.00(-617.29 ;-98.71)$ & - & - & - & - & - & - & - \\
\hline Age of non-diabeti & & & & & & & & & \\
\hline $30-40$ & 1 & $-280.00(-320.73 ;-239.27)$ & - & - & & & & & \\
\hline $50-60$ & 3 & $-243.57(-440.95 ;-46.19)$ & $97.9 \%$ & $<0.001$ & $73.98(-103.31 ; 251.27)$ & 0.276 & 24367 & $97.52 \%$ & $16.41 \%$ \\
\hline $70-80$ & 1 & $16.01(-26.58 ; 58.13)$ & - & - & & & & & \\
\hline No data & 1 & $-358.00(-617.29 ;-98.71)$ & - & - & - & - & - & - & - \\
\hline
\end{tabular}


Age of non-diabetics 50 (years)

\begin{tabular}{|c|c|c|c|c|c|c|c|c|c|}
\hline$<50$ & 1 & -280.00 (-320.73; -239.27) & - & - & \multirow{3}{*}{$101.57(-580.72 ; 783.86)$} & \multirow{3}{*}{0.668} & \multirow{3}{*}{36305} & \multirow{3}{*}{$98.43 \%$} & \multirow[b]{2}{*}{$-24.55 \%$} \\
\hline$\geq 50$ & 4 & $-178.44(-369.42 ; 12.55)$ & $98.4 \%$ & $<0.001$ & & & & & \\
\hline No data & 1 & $-358.00(-617.29 ;-98.71)$ & - & - & & & & & \\
\hline \multicolumn{10}{|l|}{ Ider group II } \\
\hline Same age (1) & 4 & $-320.83(-361.46 ;-280.19)$ & $47.1 \%$ & 0.129 & \multirow{2}{*}{$-309.20(-408.99 ;-209.42)$} & \multirow{2}{*}{0.001} & \multirow{2}{*}{1012} & \multirow{2}{*}{$55.19 \%$} & \multirow{2}{*}{$96.24 \%$} \\
\hline Different age (2) & 2 & $-12.41(-70.89 ; 46.08)$ & $69.3 \%$ & 0.071 & & & & & \\
\hline \multicolumn{10}{|l|}{ uration of diabetes (years) } \\
\hline$<13$ & 2 & $-162.30(-393.83 ; 69.24)$ & $98.1 \%$ & $<0.001$ & \multirow{2}{*}{$-180.84(-692.57 ; 330.88)$} & \multirow{2}{*}{0.268} & \multirow{2}{*}{13550} & \multirow{2}{*}{$96.19 \%$} & \multirow{2}{*}{$31.12 \%$} \\
\hline$\geq 13$ & 2 & $-343.86(-379.36 ;-308.37)$ & $0.0 \%$ & 0.649 & & & & & \\
\hline No data & 2 & $-148.21(-512.01 ; 215.58)$ & $87.2 \%$ & 0.005 & - & - & - & - & - \\
\hline \multicolumn{10}{|l|}{ ample size } \\
\hline$<150$ & 2 & $-12.41(-70.89 ; 46.08)$ & $69.3 \%$ & 0.071 & \multirow{2}{*}{$-309.20(-408.99 ;-209.42)$} & \multirow{2}{*}{0.001} & \multirow{2}{*}{1012} & \multirow{2}{*}{$55.19 \%$} & \multirow{2}{*}{$96.24 \%$} \\
\hline$\geq 150$ & 4 & $-320.83(-361.46 ;-280.19)$ & $47.1 \%$ & 0.129 & & & & & \\
\hline \multicolumn{10}{|l|}{ latched } \\
\hline No matched & 2 & $-12.41(-70.89 ; 46.08)$ & $69.3 \%$ & 0.071 & \multirow{3}{*}{$-309.20(-408.99 ;-209.42)$} & \multirow{3}{*}{0.001} & \multirow{3}{*}{1012} & \multirow{3}{*}{$55.19 \%$} & \multirow{3}{*}{$96.24 \%$} \\
\hline $\begin{array}{l}\text { Matched by age, gender } \\
\text { weight }\end{array}$ & 4 & $-320.83(-361.46 ;-280.19)$ & $47.1 \%$ & 0.129 & & & & & \\
\hline inc assessment method & & & & & & & & & \\
\hline ASS & 4 & $-237.46(-411.56 ;-63.35)$ & $98.3 \%$ & $<0.001$ & \multirow{2}{*}{$69.65(-389.57 ; 528.86)$} & \multirow{2}{*}{0.695} & \multirow{2}{*}{31017} & \multirow{2}{*}{$97.80 \%$} & \multirow{2}{*}{$-15.21 \%$} \\
\hline ICP & 2 & $-174.03(-477.49 ; 129.42)$ & $81.6 \%$ & 0.020 & & & & & \\
\hline
\end{tabular}

AAS (Atomic Absorption Spectrophotometry), ICP (Inductively coupled plasma), EAAS (Electrothermal Atomic Absorption Spectroscopy). 
Without complications of diabetes

Rauscher, 1997 (United Kingdom, Europe) women Rauscher, 1997 (United Kingdom, Europe) men Al-Maroof, 2006 (Iraq, Asia) men / women de Sousa Lima, 2011 (Brazil, America) men de Sousa Lima, 2011 (Brazil, America) women Foster, 2012 (Australia, Oceania) women Subtotal (l-squared $=0.0 \%, p=0.640$ )

With complications of diabetes Lee, 2005 (Korea, Asia) women Batista, 2006 (Sao Paulo, America) women Batista, 2006 (Sao Paulo, America) men Subtotal (l-squared $=11.9 \%, p=0.321$ )

Overall $(l-$ squared $=61.0 \%, p=0.009)$

NOTE: Weights are from random effects analysis

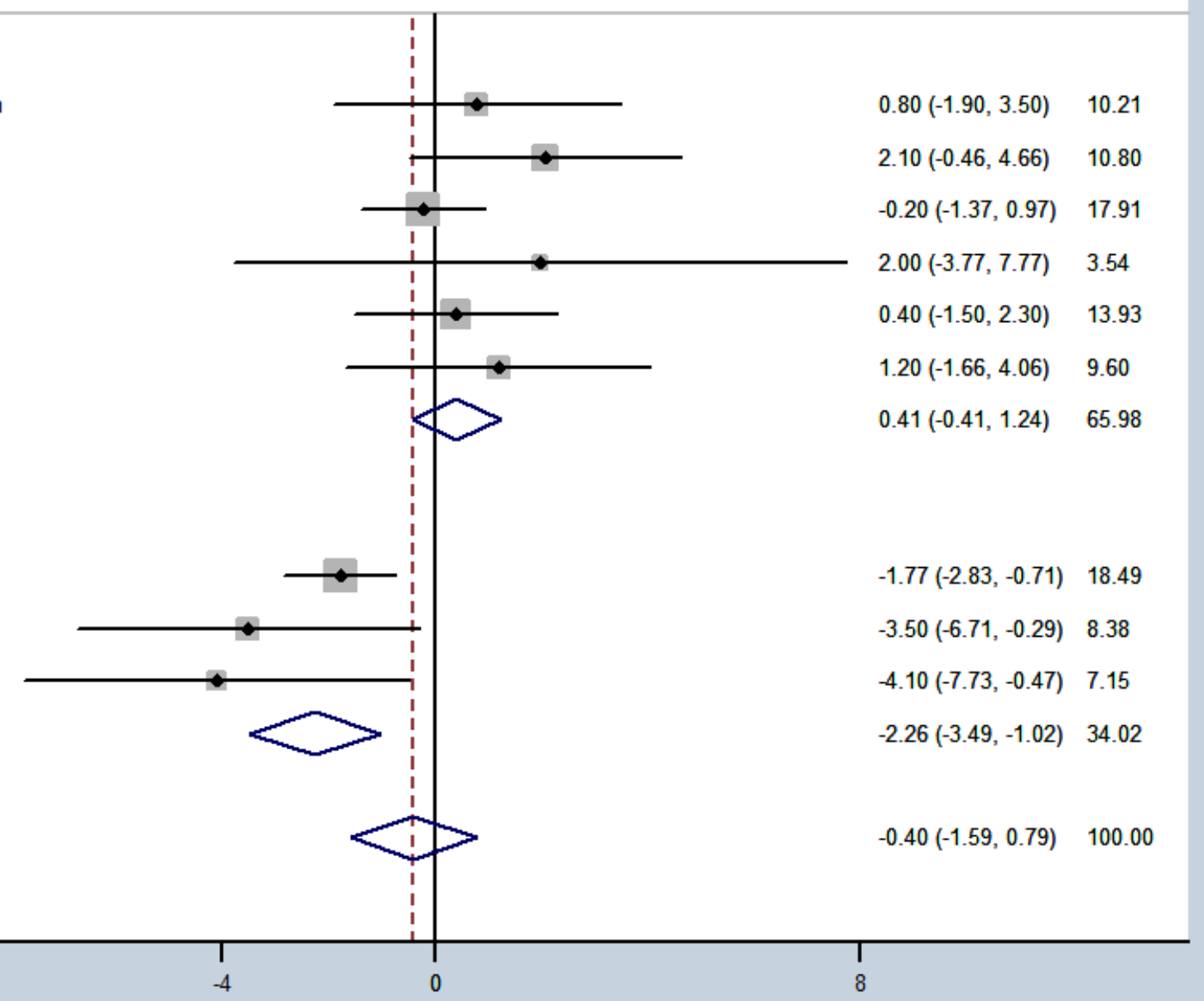




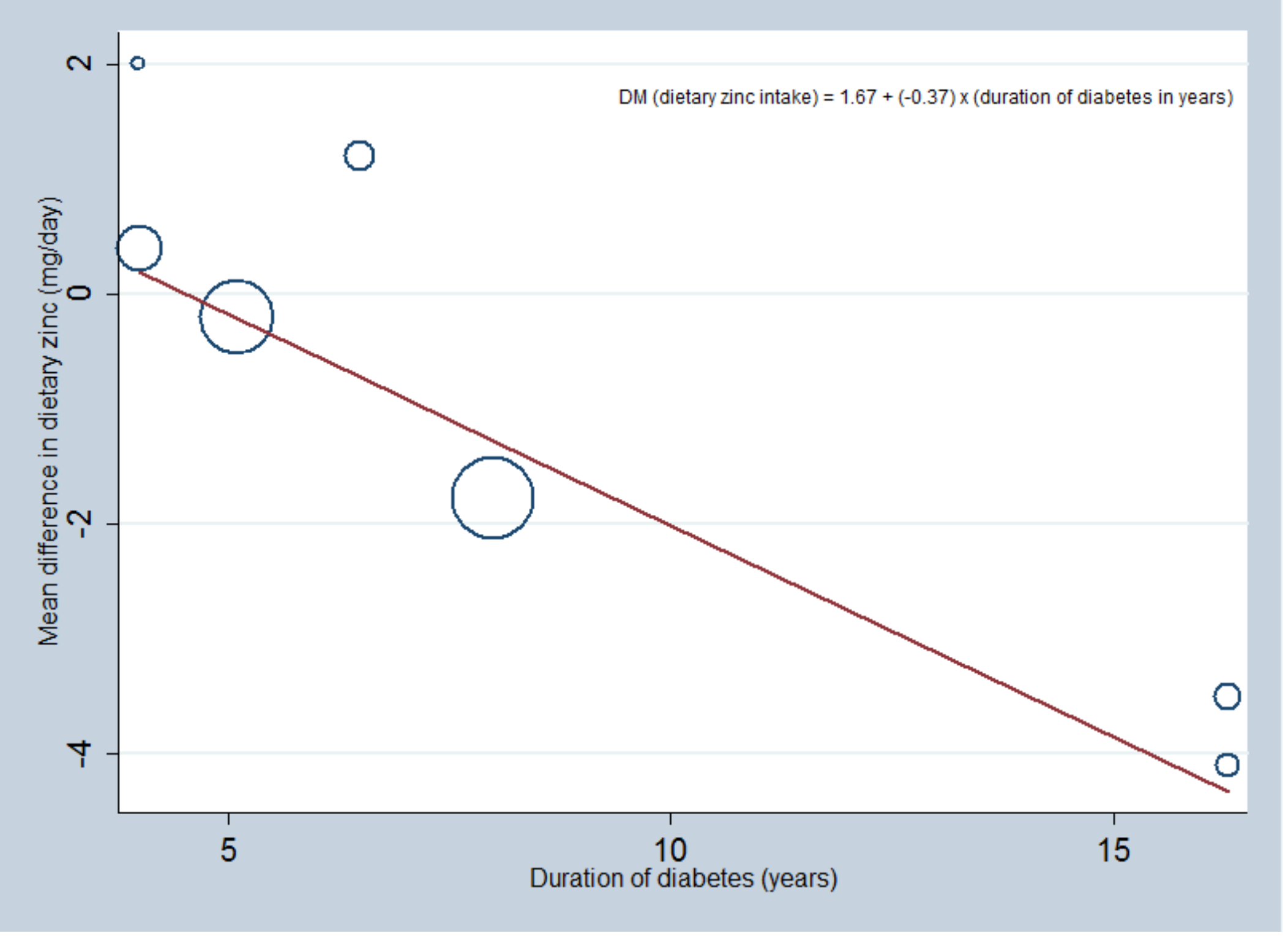




\section{Western}

Ekmekcioglu, 2001 (Austria, Europe)

Forte, 2013 (Italy, Europe) women/men

Subtotal (I-squared $=69.3 \%, p=0.071$ )

\section{Esstern}

Kazi, 2008 (Pakistan, Asia) men

Kazi, 2008 (Pakistan, Asia) women

Afridi, 2009 (Pakistan, Asia) women

Chen, 2012 (China, Asia)

Subtotal (I-squared $=47.1 \%, p=0.129$ )

.

Overall (1-squared $=97.7 \%, P=0.000)$

NOTE: Weights are from random effects analysis

$-620$

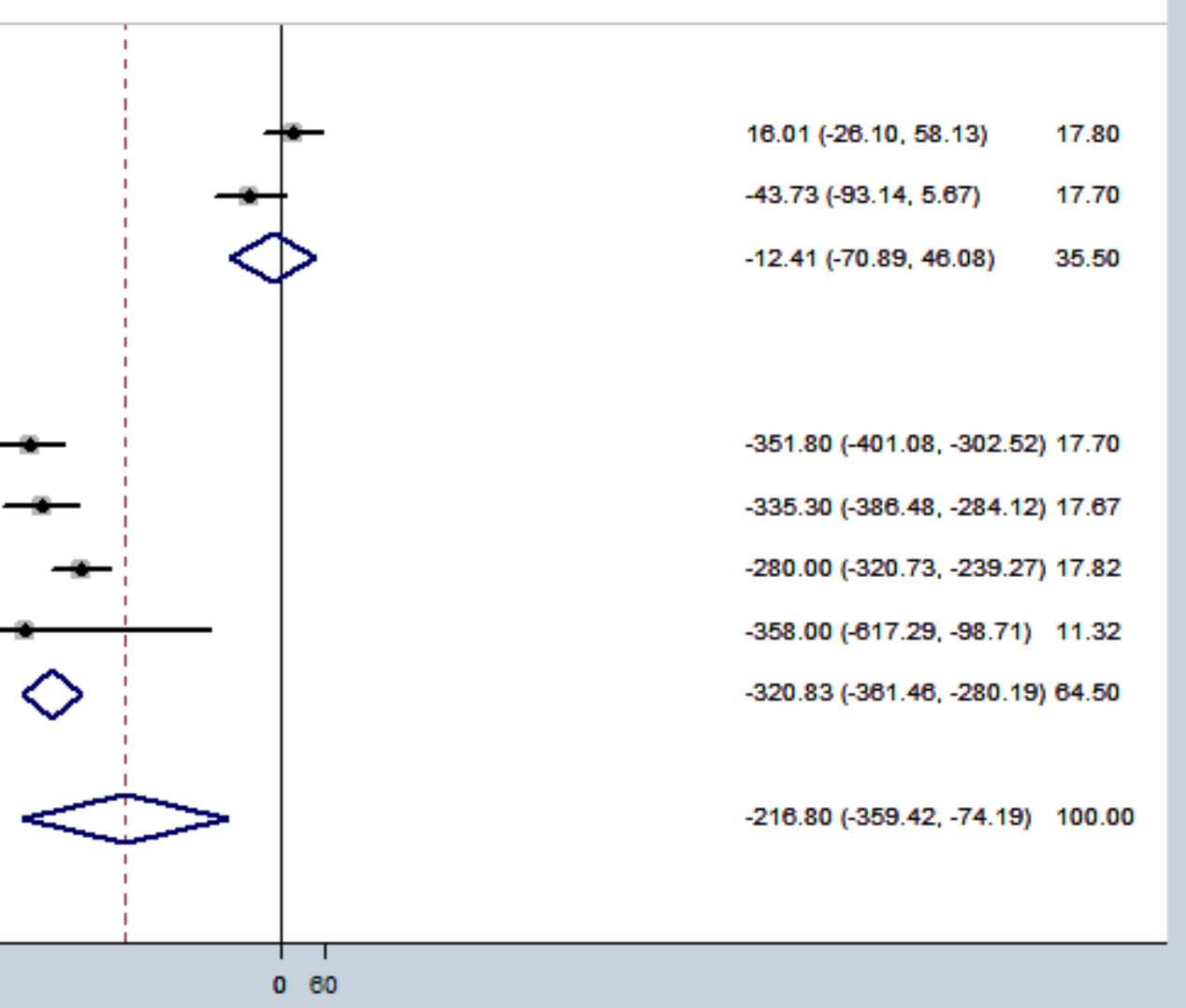




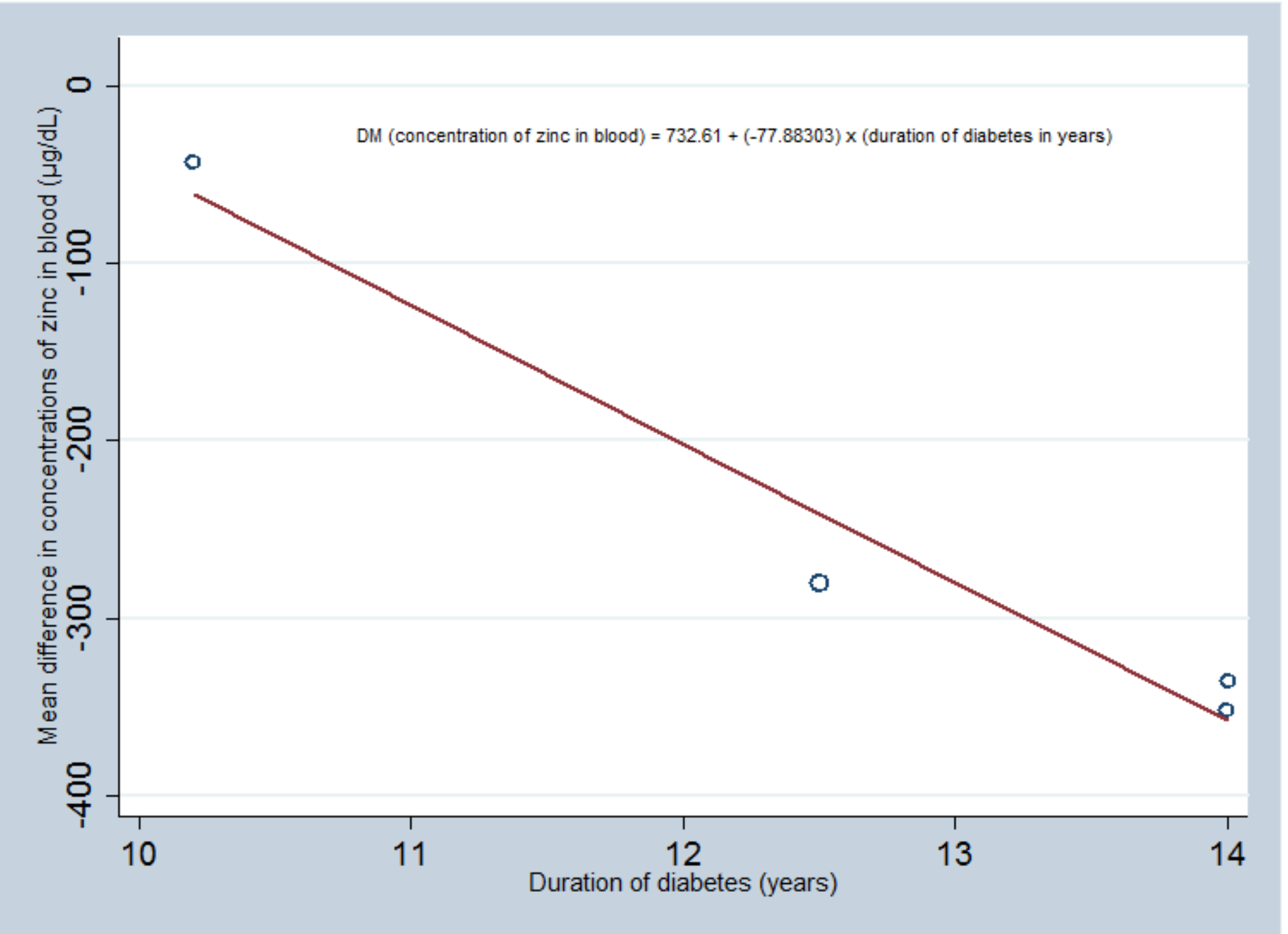




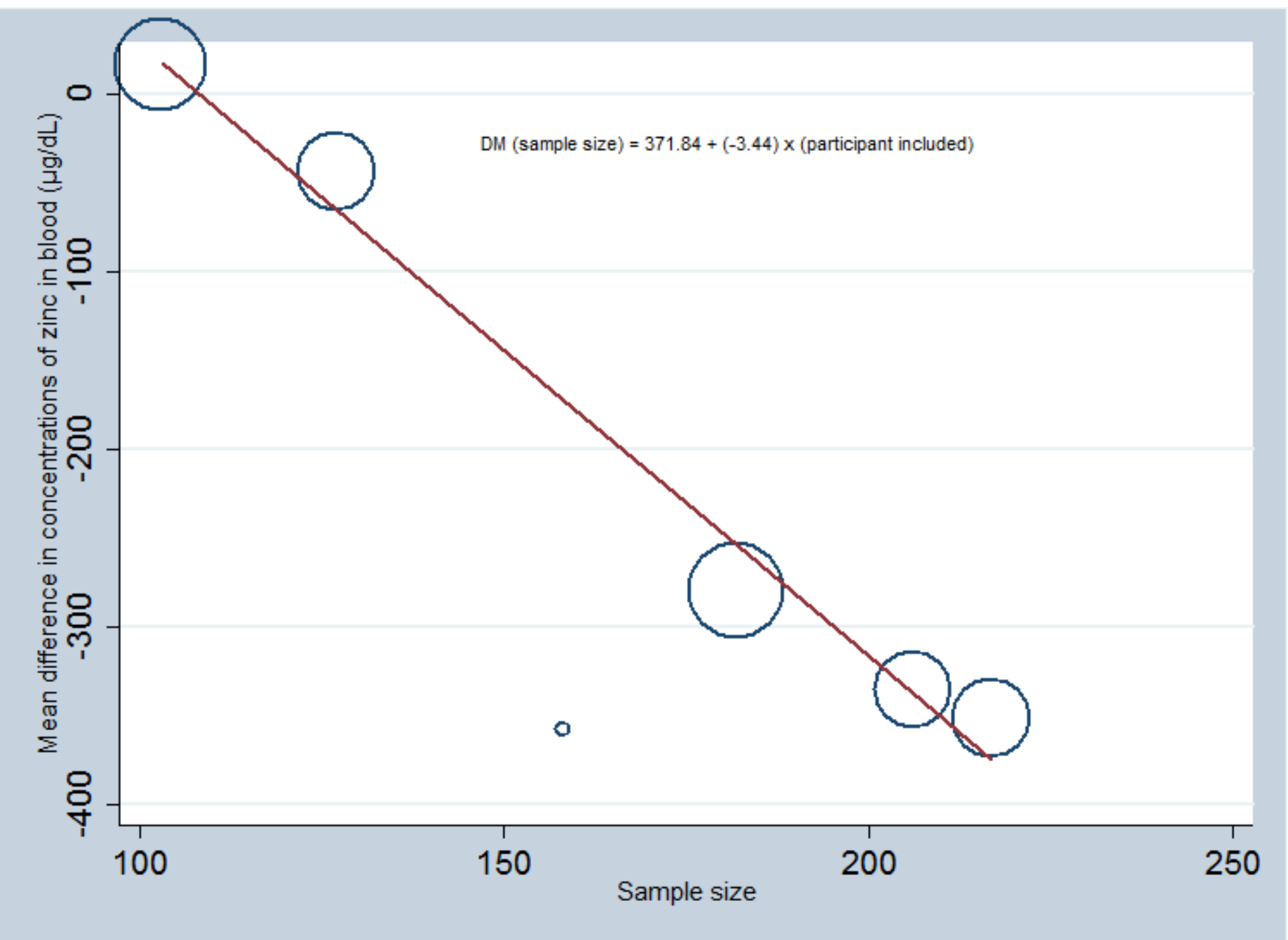

